\title{
EPISTEMIC VIOLENCE: A CASE FOR THE DECOLONISATION OF SOUTH AFRICAN BUSINESS SCHOOL CURRICULA
}

\author{
F. Schutte \\ Research Associate \\ Gordon Institute of Business Science (GIBS) \\ University of Pretoria \\ e-mail: pjwschutte@telkomsa.net
}

\section{ABSTRACT}

Since the \#FeesMustFall movement and student protests of 2015 the decolonisation debate has become part of the ongoing narrative in South Africa regarding tertiary education. This article is investigating the concept of decolonisation and to identify different possibilities for the rethinking of decolonising the academic body of knowledge and the production of knowledge in the environment of tertiary education, of which business schools are a part. A systematic review of relevant and existing literature has been concluded. The findings of this review have shown that decolonisation is non-negotiable. Inclusive research from an African perspective can act as a starting point for this comprehensive project that is slowly starting to gain momentum. The project may benefit Africa and the West by providing a better understanding of each other when entering the same global market space.

Keywords: colonisation, decolonisation, curriculum, epistemic violence, business school

\section{INTRODUCTION}

This article is part of a more comprehensive and ongoing research project on decolonisation, and the implications and impact it might have on the future of business school curriculum development. The research project will investigate ways which might contribute to and support the suggested decolonisation process and it will consider options to address the issues regarding curriculum content and the possibility of decolonising the curriculum.

The ongoing debate in South Africa regarding the decolonisation of tertiary institutions and its curricula has been caused by the student protests of 2015 and the ongoing narrative of the former minister of Higher Education, Blade Nzimande. The national government's reaction to the student protests and the \#FeesMustFall-movement was to announce no increases for 2016 and 2017 in any fees and to announce free education to be implemented from 2018, without any information of the funding process. These actions are a political move and window-dressing of the problem and they do not even closely address the root cause.

From a wider perspective, to criticise forms of Western knowledge is an ongoing 
phenomenon. As a model of being a university, the Kantian-Humboldtian exemplary has, during the last decade, at numerous occasions, been criticized by post-colonial intellectuals who call for the decolonialisation of philosophies within the social sciences (Boiden, Cohen and Grosfoguel 2012). This article will serve as a broad introduction to present the issue of decolonisation for debate and further research in business schools.

\section{THE PROBLEM INVESTIGATED}

Decolonising curricula within higher education, according to Blade Nzimande (2017), the former South African minister of Higher Education, is no small matter but it is an imperative. Epistemologies, the role of language, methodologies and systems to produce new knowledge have to be interrogated to find ways in which education can become a possibility for deepening democracy. The future mantra, according to him, for human development and community engagement, must be the Africanisation of education through decolonisation. However, he also warns that he is not in favour of a university system where exclusivist black privilege only replaces the previous white exclusivist privilege. His agenda is to eradicate the inheritance of patriarchy and racist oppression while building African universities without going back to the "Stone Age". South African universities must not only be consumers of knowledge; they should be globally engaged, also as producers of relevant global and local knowledge (Heleta 2016).

The decolonisation of knowledge and the curriculum is especially challenging for business schools, because business schools have been turned into marketable products and the competition among them to produce the best and globally acceptable candidates is fierce. According to Mbembe (2015), South African universities must reposition themselves and not attempt to attract European or American students or try to deliver students for those markets. With a decolonised curriculum, South Africa must redesign its tuition system, revamp immigration policies and open new paths to citizenship for all African nations. South Africa is in an excellent situation to develop diasporic knowledge networks. These networks can empower intellectuals with African backgrounds from the rest of the world to bring their skills to South Africa. South African universities and business schools have a good stance to develop programmes which focus on Africa and that will nurture new networks with academics worldwide.

According to Ruggunan (2016), some curriculum content that needs immediate decolonisation is management studies. He motivates this by explaining that studies in management are at the moment wedged between the Anglo-Saxon and the Afrikaner-nationalist narratives. For him decolonisation is not the substitution of one knowledge-production model that legitimates colonial managerial dominance within the study of management with an 
indigenous African nationalist model of dominance and control. Decolonisation also does not mean that African-authored textbooks must replace the Euro-North-American textbooks which advocate just the same ideologies. Ruggunan (2016) maintains that the reason why management studies must be decolonised, is due to a form of epistemic violence in the core curriculum. To define epistemic violence, Heleta (2016) in the same semantic field as Gayatri Spivak, defined epistemic violence as the suppression and domination of former colonial subjects through knowledge systems by Eurocentric and Western ideologies. According to Ruggunan, the curriculum is showing the inferiority and problematizing the Other, mainly black, who in this case are the employees. The subject of the epistemic violence, is the researcher, because the research is directed at the worker, who is the Other. The Marikana incident has shown that the Other is expandable.

In the same spirit, Professor Rajendra Chetty, head of research and postgraduate studies at the University of Technology in the Cape Peninsula, also states that business school curricula need to be decolonised on this very point because they do not address workers' rights (DHET 2016). The British Council on Higher Education agrees that the decolonisation of curricula at South African business schools can be a powerful catalyst for change by achieving national economic, political and social development goals in a grossly unequal world (DHET 2016).

The Graduate School of Business of the University of Cape Town, as well as the Wits Business School Case Centre, have started to address the issue of the decolonisation of the curriculum by developing local case studies for their teaching of business subjects. Up to now first world examples have been used, mostly from Harvard Business School. With this project they develop business case studies focused on African social and economic realities that will become relevant teaching material. This is a beginning for the creation of Africa focused business learning material. The idea with this project is to compose case studies with an African flavour which can be used globally because business emerging markets need the rest of the world to invest and operate within its markets. Therefore, to understand Africa, they need access to this type of curriculum content (UCT 2016).

The development of a decolonised MBA or any other business degree asks for more than just case studies with an African flair. Future research needs also to be done on indigenous knowledge regarding concepts such as sustainability, business ethics, negotiation techniques, leadership, hierarchy, profit and loss, investments, insurance, ownership, accountability, long term planning, indigenous township and rural marketing, time management, risk management, procurement planning, street vendors, contracts and agreements, accounting principles, economic growth, budgeting, banking, infrastructure development, change management, paradigm shifts, innovation, entrepreneurship, responsibility, citizenship, tax, team work, 
quality management, organisational structures, decision-making processes, future studies and many more. The practice of business in South Africa has proved that a Eurocentric understanding of these concepts differs in some instances from indigenous African knowledge. Therefore, research into the indigenous understanding of concepts like these is necessary to find common ground and a workable platform for Africa and the West to understand each other when entering global business relations.

The Slovenian philosopher Žižek (2009) recounts an old story in his book, Violence, about an employee mistrusted for taking things that doesn't belong to him. Whenever he knocks off, they check his wheelbarrow carefully, but the security personnel do not find anything amiss. One day, the penny drops: the employee is taking the wheelbarrows themselves. The bottom line of the narrative is that we often emphasise the objects of our inquiry without noticing the carriers of the objects of inquiry. Applied to the topic of this article, one may view the curriculum as a carrier of violence - epistemic violence - and this becomes a continuity of colonialism. The curriculum, as a possible carrier of violence, and as a continuation of colonialism thus needs further investigation within the context of decolonisation.

\section{RESEARCH OBJECTIVES}

The objectives of this article are to investigate the literature to

- Define the concept of decolonisation, and

- Identify possibilities for the rethinking of the decolonisation of academic knowledge production within the environment of higher education, especially within business schools.

\section{LITERATURE REVIEW}

\section{Education}

The university as institution has existed for more than 900 years. It therefore makes sense to ask questions about the future of the university as institution. Universities are cardinal institutions for the creation of knowledge and are ranked according to their ability to create knowledge (Barnett and Bengtsen 2017).

African universities have been molded according to the European colonial model (Le Grange 2014). This model, based on Western subject knowledge, of being a university, has not been redressed in post-apartheid times (Le Grange 2016). One of the central colonial activities during the British and French control of Africa was education (Takayama, Sriprakash and 
Connell 2016). According to Biney (2016), Westerners spread their knowledge through Christianity and branded it as the only truthful and universal knowledge across the globe to displace existing indigenous knowledge systems. When conquered colonised peoples understood what was happening to them because they lost their own cultural and intellectual traditions on which their lives were built when they were forced to adopt a new system. What makes the challenge of decolonisation more complicated is the phenomenon that indigenous Africans inspired by colonial hierarchies, education, lifestyle and knowledge, encourage their children to become Western through self-cultivation assimilation (Nyamnjoh 2016). According to Biney (2016), one of the consequences of the curriculum is the production of black skins in white masks; therefore, not only the university structure but the entire curriculum needs to be decolonised. De Oliveira Andreotti, Stein, Ahenakew and Hunt (2015) call colonised education one of the violences of modernity, the imposition of systemic violence on others, and they emphasise the fact that decolonisation is vital pedagogical work.

The demographics of the students, in post-apartheid have changed at South African universities but the demographics of intellectuals at the universities have not changed in accordance. These student demographic changes, in a sense, has protected the prospectuses of the colonial era. Mbembe (2015) and others therefore call for the decolonisation not only of staff demographics, but also of lecture halls, names, statues and public spaces. They want to see the transformation of the university classroom as one without walls in which all are colearners

The canon of universities in the western world is characterised by both Euro centricity and masculinity. According to Biney (2016), there is a perception that knowledge and an epistemology about Africans can only be produced by Europeans. This mind set of imperialracial-patriarchy is also existing in Ivy League institutions. Numerous European scholars hardly cite African scholars in their works. They only cite other Europeans. Epistemic racism, Eurocentrism and sexism are frequently questioned by decolonial or post-colonial intellectuals that guide knowledge production and academic practices in Euro-American universities. These theories are critiqued because they are based on traditions and shaped nearly always by. They are often assumed to be the only ones capable of researching universality. Therefore, they are considered to be justly foundational to Westernised institutions of social sciences and humanities. Critiques also query the possibility of total encyclopaedic anthropological knowledge. Producing anthropological knowledge is a process of knowing about the Other while never fully acknowledging these Others as thinking and knowledge-producing subjects (Boiden et al. 2012). This underlines the complaint by black students, according to Heleta (2016), that university lectures do not reflect their own lived experiences. They are the Other, 
mentioned above, who are only valued and recognised, when they conform. For black African students, decolonisation involves the reframing reconsidering of curricula by placing Africa central in research, teaching and learning. Currently, black students in class are confronted by texts and epistemological content that deny their dreams, history and lived experiences. Africa and its complexities are not high on the list of prescribed topics discussed in class (Heleta 2016).

According to Grosfoguel (2012), Eurocentrism is an epistemic perspective that throughout the world, privileges the knowledge systems of the Euro-male colonisers. This epistemology is globally institutionalised. To rise above this structure asks for a pluriversity instead of a university to produce decolonial social sciences and humanities. Colonialism did come formally to an end with the departure of colonial administrators from the colonised regions, coloniality survived. It is maintained in books, in the curricula and in the criteria for academic performance (Biney 2016).

What universities need (Grosfoguel 2012) is a decolonised space where Euro-American social sciences have to lose their privileged position to no longer be the only source of valid knowledge but to be only voice one among others. This decolonised new space must be conducive to the production of decolonial social sciences. Biney's (2016) view on this is that the elephant in the room is white supremacy and that the project to decolonise academia should be an all-encompassing task to transform not only the university, but society at large, of which the university is a part.

For the university of the future, academics must develop a capacity, according to Barnett and Bengtsen (2017), and a readiness to let go and to free itself to exist in a new way, lose from old assurances and comfortable philosophies. One cannot arrive at the future without breaking networks of knowledge on your way. The university must realise that it no longer has a monopoly on the production of knowledge. Higher education in future must recognise its dependency on other role players such as ordinary citizens, indigenous communities, industry and government when it comes to research and knowledge creation (Le Grange 2014).

\section{Decolonisation}

Coloniality can be understood, according to Maldonado-Torres (2007), as a structure defining the organisation and dissemination of epistemic, material and aesthetic resources. This dissemination happens in ways that reproduce modernity's imperial projects, such as spaciality, which is the expansionist control of lands, ontoepistic racism, which is the elimination and subjugation of difference, and epistemic violence, which is the geopolitics of knowledge production. All of these are constitutive of modernity. According to Alfred (2004), colonialism is a total power relation and it must be seen in connection with indigenous people's loss of self- 
determination to live as indigenous people. This produced, according to Alexander (2005) the crumbling and splitting off at both the physical and mental levels. What is of concern is the fact that domination continues to even long after formal colonialism has come to a close (Baldwin 2012). Coloniality is thus still alive and well even though colonialism is over (GaztambideFernández 2014).

Colonisation endeavoured, according to Flemming (2016), to control the memory of the colonised by mutilating their memory in a process of cultural subjugation through controlling the education system. This is what Odora Hoppers and Richards (2011) call second level colonialism. Silva (2007) adds that colonialism is therefore the overrepresentation of the white, bourgeois, male, who rationalises his dominion over those he deems to be irrational, vulnerable and inferior.

Nyamnjoh (2016) brings a more political perspective to the debate when he argues that colonisation expected African people to trample on their past primitiveness and to whiten-up in order to be counted as progressive. This action is not only dehumanising but it also denies Africans their right to identity and self-esteem during what Mbembe (2001) calls a long lifedenying history. Any decolonising project must address these issues and restore dignity, transform structures that have sustained racism up to now, and transform curricula across academic institutions. Nyamnjoh admits that it requires careful thinking to get it right, it will therefore be a permanent work in progress.

According to Chilisa (2012), there are five stages in the process of decolonisation. The first stage is rediscover and recover. This is when people who have been colonised, find and recover the culture, identity, history and language that belonged to them. The next stage is called mourning. This is when the world's colonised people are lamenting the ongoing assault on their identity and social reality. The third phase is dreaming. This happens when colonised peoples imagine alternative possibilities for their own knowledge systems, histories and worldviews. The fourth stage is commitment. This happens when students (and others) demonstrate commitment by including their voices to those of the colonised. Lastly action as phase is when dreams and commitment become a strategy for social transformation.

An essential response to the first two generations of colonised and the recent wave of neoliberalism, is decolonisation, according to Le Grange (2016) The first phase of colonialism was the conquering of land and bodies while second wave was the colonisation of the mind. This happened according to Le Grange by means of education, science, economics and law. Neocolonialism, in countries who experience their post-independence phase, contributes to this situation because new elites took on the role of colonialists, because they were trained and influenced by colonialists. 
Educational projects that involve the dissimilarities between humans, their history, and knowledge, bring a process of decolonising forth, but the task is not an easy one because the colonial connection is intensely entrenched in the education, and especially the university and research environment (Takayama et al. 2016).

\section{Curriculum}

There are different views on what constitutes a curriculum. Grumet (1981) has an autobiographical view on curriculum. She describes it as the narratives we share with students regarding the past, present and future. The question can thus be asked: Who tells the stories? In a sense Gaztambide-Fernández (2012) shares this point of view by stating that curriculum is to address the self. Curriculum is about the knowledge individual should have, or skills needed, or about a personal interpretation of experiences which shapes a person's perspective toward difference.

Aoki (1999) distinguishes between the way in which a curriculum is structured and the way in which it is lived. From this point of view, the current university curriculum can be used as a basis for decolonisation. He also distinguishes between explicit, unseen and null curricula. An explicit one consists of all the formalities, namely the module outlines, assignments and textbooks, in other words, the content that is provided to students. The unseen part of the curriculum is subtext, namely the university's values and culture. The null curriculum is what is left out by universities and thus not taught and learned.

Jason Wallin (2010) suggests that curriculum can be thought of as a force which constantly conceptualise without closeness or fixity. It implies constant innovation, creating things that does not exist yet, experimentation, and the development of dissimilarity and movement. The curriculum therefore creates a basis for decolonisation.

Le Grange (2016) proposes that decolonisation of the curriculum not necessarily implies the abolishing Western knowledge. It rather has to decentre or deterritorialise it, and to develop gender and culturally inclusive curricula (Le Grange 2014). Grosfoguel (2012) also argues against dismissing the important contribution of Western knowledge production; however, one has to definitely question the colonial Eurocentric nature of mainstream disciplines. The reason for this, according to Heleta (2016), is that almost all African academics are moulded by Western knowledge and they are often unwilling to reject their own paradigm by pulling apart their colonial knowledge systems. They can therefore easily prescribe new readings and other material under the flag of decolonisation, but what about academic's attitudes? The quest thus asks for more than just the choice of materials. Are academics willing to decolonise their minds, to unlearn, learn afresh and fundamentally transform? 
The key curriculum question, according to Le Grange (2014), that has not received sufficient attention in the higher education discourses, is the question "What knowledge is of most worth in post-apartheid South Africa?". To this Heleta (2016) adds, "What are the attitudes of the knowledge producers?"

\section{RESEARCH METHODOLOGY}

The methodology for this research article is linked to the purpose, namely to define the concept of decolonisation (which was done as part of the literature review), and to identify possibilities for the rethinking of decolonisation of academic knowledge production in the environment of higher education, especially in business schools, by doing an analysis of the relevant existing literature.

A review is designed to reduce bias. It is a replicable, scientific and transparent process (White and Schmidt 2005; Bryman and Bell 2017)) through exhaustive literature searches of published and unpublished studies (Bryman and Bell 2017) to select and assess sources and (Nightingale 2009), to combine results of the reviewed studies with the aim to critique the findings by which the individual studies are integrated to produce a coherent summary (Green, Johnson and Adams 2006).

According to Bryman and Bell (2017), the three main steps of the systematic review process are to specify the research question, to conduct the research and to report and disseminate. For this article the main focus of the above-mentioned research questions was to identify possibilities for the decolonisation process at universities. A literature search has been undertaken and the results are reported in the Findings section of this article. A few preliminary remarks are made in the Conclusion section. As this article is part of a more comprehensive and ongoing research project, some information in this article can later be reworked as part of a next publication if new and more recent data and perspectives on the issue become available.

\section{FINDINGS}

The question of how to decolonise academia in South Africa is important to address. According to Biney (2016), a project like this asks for political will and fundamental inventiveness from university management. They not only have to listen to African student voices and scholars, they genuinely have to implement change. Decolonising is not to tick a diversity or equal opportunity box, or to only increase black student numbers, it is also to address structures, the European epistemic body of knowledge the reins of power, and the way in which universities think (Biney 2016). It is also not about adding black thinking to a white pot. It is about accepting the plurality and equality of knowledge, and to learn to unlearn in order to relearn. It necessitates 
intellectual modesty and academic rigour.

The following theories have been identified during the systematic review as possibilities for the rethinking of decolonisation of academic knowledge production in the environment of higher education. Different authors who wrote on this topic as well as a summary of their core philosophies have been listed and summarised below.

\section{Frantz Fanon - Subversion of the law of repetition}

Calls to decolonise are not new. Frantz Fanon (1969) already theorised about it in the 1960s. For Fanon, self-ownership was the most important struggle when it comes to decolonisation. It is a struggle to take back what belongs to you. It is to repossess. Decolonisation for Fanon (1969) is about reshaping, but to reshape without looking at pre-existing models as paradigms. He thus rejects imitation and mimicry. He asks for something different and new because decolonisation is a time for closure and a time of possibility.

Decolonisation has to be an occurrence that need to redefine a native being. It should open up the possibility that a native can become human rather than just being a thing (Fanon 1969); it thus has to create the permanent possibility of the emergence of the not yet. Fanon claims that decolonisation asks for a new way of looking at men: no longer as somebody limited by their look but as a person who's essence coincides with their image, but then image not as something separate from them, but as something belonging to them. Decolonisation is thus the removal of the breach between essence and image. For Fanon it is about reconnecting the essence to the image so that the person can exist in itself and not as something unworthy.

\section{Ngugi wa Thiongó - Decolonising the mind}

The philosophy behind decolonisation for Wa Thiongó (1986) is to view it as an ongoing process to see clearly. He calls upon Africans to see themselves not as separate from the rest of humanity. They must view themselves in relation to others and to themselves, because all share the universe. Decolonisation is for him not an end point, but a beginning of a new struggle. This struggle is about what is to be taught and the terms under which it should be taught.

Questions Wa Thiongó addressed are: How to handle the inherited colonial education system and the consciousness in the African mind which it incubated? Where to go with education if you want to get rid of neo-colonialism? How does Africa want her people to view themselves and their universe? From where do they have to depart to nurture this new perspective? To what resources should they be exposed to? Who would assist them in class, to make sense of that material? Does it have to be an African, if so, what kind of African? An African who has inherited the colonial world outlook or one trying to break free from that 
consciousness?

Decolonisation is thus a project of re-cantering and of discarding the idea that Africa is simply an extension Europe. Decolonisation is not an act to close the door to the West or other traditions. It is just about defining the centre namely Africa. Africa must act as the centre, not as an appendix. African languages should be at the centre of its learning and learning projects and the future African university must be multilingual instead of mono-lingual.

\section{Catherine Odora Hoppers and Howard Richards - Meta-methodology}

Odora Hoppers and Richards (2011) propose a methodology for transforming universities by transforming methodologies. They draw on three sources of meta-methodology, namely

Thomas Kuhn's work on the history of science, which entails experience they got from practices of corporations reinventing themselves in changing times within the corporate world, and what they call the ethical approach to speech acts.

From Kuhn they select two ideas, namely anomalies and concrete models. According to Kuhn, the accumulation of anomalies discredits old paradigms. The huge anomaly that they submit is the fact that an enormous accumulation of knowledge is not providing solutions to humanity's principal problems. However, the accumulation of anomalies alone do not cause paradigm shifts. Among other requisites is a concrete alternative. They additionally suggest concrete alternatives in the plural because they are advocating a multi-paradigm world in which transformative knowledge must be produced.

From the corporate world they identify four elements of successful transformation strategies, namely an awareness that there is a crisis, the development of a common vision showing how collectively to overcome the crisis, to find allies, or, to put it more eloquently, to find discursive coalitions; and, lastly, to define at each moment of the process precisely what to do next. Their plan of action is to at least contribute to creating a common vision and so doing the groundwork for finding discursive coalitions to go further while deciding what to do next.

Their third source is called humanisation in the dangerous times we live in. All speech is human action and deciding how to act is always an ethical challenge, and the responsibility to make ethical choices is what it means to be human.

What Odora Hoppers and Richards thus suggest is a framework for transformation that seeks consensus by embracing inclusiveness. It implies a search for invariant relationships as part of science, but not all of it. It regards Europeans as part of humanity, but not all of it. Modernity is part of culture, but not all of it. European knowledge systems are part of knowledge, but not all of it. The common vision must include visionaries in diverse cultures, 
each with its own way of thinking. People can thus see crises and respond to them constructively by perhaps using concepts that can be expressed in one language but not in another. This is possibly the only practical way for all humanity to see the crisis and to respond constructively. Each person is doing it differently, but embracing inclusiveness, and so, the curriculum opens.

\section{Ruben Gaztambide-Fernández - Pedagogy of solidarity}

Gaztambide-Fernández (2012) appeals to educators to take up a role in creating the circumstances for a different kind of interaction - an interaction that both compete against ongoing colonisation and one that seek out to heal the social, cultural and spiritual consequences of colonial history. The vision he offers is a pedagogy of solidarity for education, which will start pointing in the direction of new decolonised and anti-oppressive beginnings.

Pedagogy highlights the interactive and purposive character of education and is therefore transformative. A decolonising pedagogy of solidarity has thus to shift the emphasis from explaining current social arrangements and their implied colonial logic. Unity with decolonisation is to challenge the very idea of what it means to be human. One have to image relations on the premise of the connection between difference and interdependency, rather than resemblance and a rational calculation of self-interest.

Gaztambide-Fernández's pedagogy of solidarity conveys a pledge to three levels of solidarity, namely relational, transitive and creative. To state that a pedagogy of solidarity is relational, is to make a thoughtful commitment to a relational stance. It is to be with and to coexist. Transitive implies to solidarize with. It is thus an active orientation toward others in which a static position is rejected. Creative solidarity can be engaged with through words, images and other poetic modes such as gestures, music and sounds and words. It is to interact with others in unpredicted ways that can reshuffle the symbolic content of human exchanges to a kind of post-culturalism, where culture and identity can be rethought. The pedagogy of solidarity is thus not an answer but a stance to take for decolonising acts.

\section{Vanessa De Oliveira Andreotti, Sharon Stein, Cash Ahenakew and Dallas Hunt - Spaces of enunciation in response to modernity's shadow}

De Oliveira Andreotti et al. (2015) present their solution to deal with the process of decolonisation as a cartography in which they map spaces of enunciation in response to modernity's colonisation. They call these spaces a soft-reform, a radical-reform, and a beyondreform. Soft-reform refers to the process of more inclusion which can happen through institutional change in order overcome inequality by providing more resources to firstgeneration, native, previously disadvantaged, low-income students, with a view to equipping 
them with knowledge and skills, as well as a pride for their cultural to surpass existing institutional standards. However, the knowledge, skills and experience that they bring to the institution are rarely valued, except perhaps to underline cultural differences.

The enunciation of decolonisation within the radical-reform space emphasises the decolonisation of higher education as a tool to empower marginalised groups, to speak against epistemological dominance, and to reallocate resources. Modernity is seen as fixable in the sense that strategies can be mobilised to make it work for marginalised people. From this space epistemological plurality and institutional re-structuring are sought, but naturalised ontological and meta-physical possibilities remain the same.

From the beyond-reform stance, universities are seen as beyond repair, but if managed strategically, they have potential. In other words, universities must be hacked. Hacking the university implies to break ties with modernity and all perks and rewards offered by the current scheme, in favour of applying the resources for other means in order to think of providing education outside the academic walls, to investigate extra-institutional alternatives, to see universities as spaces from which to organise resistance, or to enact in anti-colonial struggles and pedagogies of decolonisation, and the decolonisation of knowledge.

\section{Achille Mbembe - The university as we knew it is dead}

According to Mbembe (2015), there are two sides to decolonisation. One is an assessment of the dominant Western academic model and the other is an effort to imagine an alternative to this model. He introduces his theory by stating that to decolonise the university is to alter it with the aim of giving it a more open cosmopolitan character.

He suggests several steps which can immediately be done while rethinking the university of the future. The first step is to create spaces at universities where black students and staff will feel safe. Secondly, he asks that the statues of persons who preached that to be black is a liability, continue to be toppled. Then he proposed that the names of spaces and buildings, as well as their interior on campus be changed, that the curriculum be reformed and that residences must be desegregated. While this is being done, close attention needs to be paid to deeper, systemic global dynamics such as the flaws and linkages in the creation of knowledge as well as the way in which it is distributed and consumed.

According to Mbembe, universities must cultivate a new vision namely to produce innovations. This will result in universities turning into an attraction for global markets which are part of the knowledge economy and therefore constantly requiring advanced technologies. Universities have consequently become very competitive and attract scholars from all over the globe, because knowledge has become a marketable product. The next logical question is: can 
South African universities compete?

Mbembe's answer is yes. Universities in South Africa must embrace their location on the African continent. They must redesign their syllabi and teaching systems, renovate the immigration policy and open South Africa to foreigners who want to work here. South Africa is in the best position in Africa to set up diasporic knowledge networks. This will empower scholars of African descent to transmit their expertise without necessarily settling here permanently. African programmes and new intra-continental academic networks must be set up. Decolonisation can be nurtured if universities invest in these diasporic intellectual networks. Decolonising knowledge is therefore not simply about de-Westernisation, it is also about building capacity for Africa.

\section{Lesley le Grange - Rethinking the subject}

According to Le Grange (2016), there are numerous methods one can take when decolonising a curriculum, however, central to these approaches are the rethinking of the subject. From a philosophical perspective, Le Grange suggests that decolonising must involve liberation from the Cartesian duality. There must be a move from cogito ergo sum to Ubuntu. Thus, from a Western individualism to a more ecological approach. Le Grange introduces the 4R's, namely relational accountability, respectful representation, reciprocal appropriation, and rights and regulation, as basis central to decolonising the curriculum and to back an emerging indigenous paradigm.

Le Grange (2016) proposes different possibilities, namely, firstly, the radical rethinking of Western disciplines, secondly, the emergence of transdisciplinary knowledge, thirdly, the creation of so-called third spaces where Western epistemologies are not destroyed but decentred so that apparently dissimilar knowledges can be fairly compared and where different knowledges can function together. Fourthly, Le Grange suggests an approach where students can discover the human origins together, as well as the epistemologies that emerged from the Cradle of Humankind. The fifth option is a compromise on the curriculum pathway between ancestral sciences, Western sciences and inter-culturality.

\section{CONCLUSION}

It is crucial, according to Le Grange (2016), to decolonise universities in South Africa as well as the curricula. It is, however, not an easy task. It is also not an event but a process. It is about a collective rethinking (Takayama et al. 2016), almost like to improvise music, especially jazz where every musician is a composer (Le Grange 2014). It is to search for a world in which there is space for many worlds (Biney 2016). New ways of living can't be created by going back to 
the Stone Age and reverse technology. New ways have to be found in reacting to events as latent carriers of promising possibilities. Knowledge production must be transgressive and it must take no prisoners (Barnett and Bengtsen 2017) Knowledge have to be produced around particular problems in the world. It has to be pursued by interdisciplinary players momentarily coming together. Once a problem has been solved, they have to disband again. The question remains whether the European university, as we know it, can successfully reinvent itself as a centre of knowledge in a globalising society in which there will be many other centres as well (Boiden et al. 2012).

It is obvious from the Findings section that decolonising the curriculum, the university and higher education is a non-negotiable. It also becomes clear that everybody agrees on the fact that it is not going to happen overnight. There is also consensus that decolonisation does not mean ignoring the results of modern research, eliminating Western knowledge or moving backwards to a pre-technological age. The focus is on the way forward from the present. Most researchers also agree on the dialectic tension between Euro-American knowledge and indigenous African knowledge that must co-exist in the same space without the one being dominant. Trying to spell out the way forward would only result in the creation of another theory about decolonisation. A recommendation in this regard is that researchers must change their stance and their attitude to acknowledge the fact that we are creating knowledge on African soil for African usage. This will help us to think inclusively and participatively, and to allow more perspectives within the same space. Thus, in a decolonising environment at a higher institution, Africa must be at the centre and the knowledge production must be plural and equal.

This research project will endeavour to further contribute to the creation of indigenous case studies that can form part of the study of business practices in a South African context; it will conduct research on all the concepts mentioned above in an attempt to find the indigenous definitions of business concepts, and by doing that, enabling the definitions to co-exist with and enrich Euro-American business concepts and definitions which are currently accepted in business schools as the only and dominant body of knowledge. The journey has just begun.

\section{REFERENCES}

Alexander, J. 2005. Pedagogies of crossing: Meditations on feminism, sexual politics, memory, and the sacred. Durham: Duke University Press.

Alfred, T. 2004. Warrior scholarship: Seeing the university as a ground of contention. In Indigenizing the academy: Transforming scholarship and empowering communities, ed. D. A. Mihesuah and A. C. Wilson, 89-99. Lincoln: University of Nebraska Press.

Aoki, T. 1999. Rethinking curriculum and pedagogy. Kappa Delta Pi Record Summer: 180- 181.

Baldwin, A. 2012. Whiteness and futurity: Towards a research agenda. Progress in Human Geography 36(2): 172-187. 
Barnett, R. and S. Bengtsen. 2017. Universities and epistemology: From a dissolution of knowledge to the emergence of a new thinking. Educ. Sci 7(1). doi: 10.3390/educsci7010038

Biney, A. 2016. Unveiling white supremacy in the academy. The Journal of Pan African Studies 9(4): 383-390.

Boiden, C., J. Cohen and R. Grosfoguel. 2012. Introduction: From university to pluriversity. A decolonial approach to the present crisis of Western universities. Human Architecture: Journal of the Sociology of Self-knowledge 10(1): 1-6.

Bryman, A. and E. Bell. 2017. Research methodology. Business and management contexts. Cape Town: Oxford.

Chilisa, B. 2012. Indigenous research methodologies. Los Angeles: Sage publications.

De Oliveira Andreotti, V., S. Stein, C. Ahenakew and D. Hunt. 2015. Mapping interpretations of decolonization in the context of higher education. Decolonization: Indigeneity, Education \& Society 4(1): 21-40.

Department Higher Education and Training. 2016. "Decolonisation" of curricula. DHET News eBulletin, 14 September 2016. http://www.dhetnews.co.za/decolonisation-or-curricula/

DHET see Department Higher Education and Training.

Fanon, F. 1969. The wreched of the earth. New York: Grove Press.

Flemming, T. K. 2016. From one colonial situation to another: Politics, universalism and the crisis of the African intellectual. The Journal of Pan African Studies 9(4): 289-317.

Gaztambide-Fernández, R. A. 2012. Decolonization and the pedagogy of solidarity. Decolonizing: Indigeneity, Education \& Society 1(1): 41-67.

Gaztambide-Fernández, R. A. 2014. Decolonial options and artistic/aestheSic entanglements: An interview with Walter Mignolo. Decolonization: Indigeneity, Education \& Society 3(1): 196-212.

Green, B. N., C. D. Johnson and A. Adams. 2006. Writing narrative literature reviews for peer- reviewed journals: Secrets of the trade. Journal of Chiropractic Medicine 5(3): 102-117.

Grosfoguel, R. 2012. The dilemmas of ethnic studies in the United Stated: Between liberal multiculturism, identity politics, disciplinary colonization, and decolonial epistemologies. Human Architecture: Journal of the Sociology of Self-Knowledge 10(1): 81-89.

Grumet, M. R. 1981. Restitution and reconstruction of educational experience: An autobiographical method for curriculum theory. In Rethinking curriculum studies: A radical approach, ed. M. Lawn and L. Barton, 115-130. London: Croom Helm.

Heleta, S. 2016. Decolonisation: Academics must change what they teach, and how. https://theconversation.com/68080. Nelson Mandela Metropolitan University.

Le Grange, L. 2014. Currere's active force and the Africanisation of the university curriculum. South African Journal for Higher Education 28(4): 1283-1294.

Le Grange, L. 2016. Decolonising the university curriculum. South African Journal of Higher Education 30(2): 1-12. http://dx.doi.org/10.20853/30-2-709

Maldonado-Torres, N. 2007. On the coloniality of being. Cultural Studies 21(2-3): 240-270.

Mbembe, A. 2001. On the postcolony. Johannesburg: Wits University Press.

Mbembe, A. 2015. Decolonizing knowledge and the question of the archive. http://wiser.wits. ac.za/system/files/Achille\%20Mbembe\%20-Decolonizing\%20Knowledge \%20and\%20 the\%20Question\%20of\%20the\%20Archive.pdf (Accessed 23 April 2017).

Nightingale, A. 2009. A guide to systematic literature reviews. Surgery 27(9): 381-384.

Nyamnjoh, F. B. 2016. Rhodes must fall: Nibbling at resilient colonialism in South Africa. Bamenda: Langaa Research and Publishing Common Initiative Group.

Nzimande, B. 2017. Address by minister of Higher Education and Training, during the inauguration of former president Thabo Mbeki as the chancellor of the Unisa, ZK Matthews Hall, Unisa, Pretoria 
(27/02/2017). http://www.polity.org.za

Odora Hoppers, C. and H. Richards. 2011. Rethinking thinking: Modernity's "other" and the transformation of the university. Pretoria: Unisa.

Ruggunan, S. D. 2016. Decolonising management studies: A love story. Acta Commercii 16(2): a412. http://dx.doi.org/10.4102/ac.v16i2.412

Silva, D. F. D. 2007. Outline of a global political subject: Reading Evo Morales's election as a (post)colonial event. Seattle Journal for Social Justice 8(1): 25-49.

Takayama, K., A. Spriprakash and R. Connell. 2016. Toward a postcolonial comparative and international education. Comparative Educational Review 61(S1).

UCT see University of Cape Town.

University of Cape Town. 2016. African case studies will help decolonise business school's curriculum. Today's news 13 May 2016. https://www.uct.ac.za/dailynews/?id=9718

Wallin, J. J. 2010. A Deleuzian approach to curriculum: Essays on a pedagogical life. New York: Palgrave Macmillan.

Wa Thiongó, N. 1986. Decolonizing the mind. New Hampshire: Heinemann.

White, A. and K. Schmidt. 2005. Systematic literature reviews. Complementary Therapies in Medicine 13: $54-60$.

Žižek, S. 2009. Violence. London: Profile Books. 